\title{
Enforcing the Laws on Public Morality against Key Populations: The Dilemma of the Ghana Police Service
}

\author{
Ndeogo ST ${ }^{*}$, Blantari $\mathrm{J}^{1}$, Awotwi $\mathrm{E}^{2}$ and Kazapoe $\mathrm{WR}^{3}$ \\ ${ }^{1}$ Ghana Police Hospital, Accra, Ghana \\ ${ }^{2}$ UNFPA, Accra, Ghana \\ ${ }^{3}$ University of Ghana, College of Basic and Applied Sciences, Legon, Accra, Ghana
}

${ }^{*}$ Corresponding author: Ndeogo ST, Ghana Police Hospital, Cantonments Accra, Ghana, Tel: +233244152975, +233302762389, E-mail: tsndeogo@gmail.com

Citation: Ndeogo ST, Blantari J, Awotwi E, Kazapoe WR (2016) Enforcing the Laws on Public Morality against Key Populations: The Dilemma of the Ghana Police Service. J Aids Hiv Infec 2(2): 202. doi: 10.15744/2454499X.2.202

Received Date: September 08, 2016 Accepted Date: October 24, 2016 Published Date: October 25, 2016

\begin{abstract}
The Ghana Police Service AIDS Control program with the support of the Ghana Country Office of UNFPA designed and implemented a program in 5 Regions and some Headquarters formations out of the total 14 establishments, focused on the epidemic of bad laws that criminalize certain populations and behaviours and thereby stand in the way of progress in addressing HIV. Followed by sensitization programs to address issues that came out from the focus group discussions. The program targeted 611 police personnel on three levels (Senior Police officers (SPO), Inspectorate/Middle level and the operational/other ranks). The ability of respondents to understand the laws and interpret them ranged for one being SPOs (77\%) to working at Domestic Violence and Victim Support Unit; (DOVVSU) (70\%) to operational men (38\%) respectively. When respondents were asked how does the Criminal Offences Act describes the offences of Solicitation or unnatural carnal knowledge, participants could mostly not define or state the key ingredients of the law as stated in the Criminal Offences Act. (Ref. Sect. 104 \& Sect 273-276 of the Criminal Offences Act 29/1960.) The response levels were SPO (62\%) DOVVSU (70\%) with Other Ranks being 59\% respectively. The third topic of discussion was; what constitutes the causation of sexual offence/offences against public morals. Appropriateness of responses ranged from DOVVSU (63\%) to SPOs (59\%) and Other Ranks (41\%). It was evident that a higher level of training correlates strongly to the proper interpretation and understanding of the application of the laws. What was obvious to the participants after the interactions was that the application of the law is often times predicated on prejudice, fear, myth and not science or evidence. This further underscores the need for sensitisation training and more of such forums to expose all wrongful practises and educate personnel on appropriate measures.
\end{abstract}

Keywords: HIV; AIDS; Police; Key Populations; DOVVSU

\section{Introduction}

The earliest cases of AIDS in Ghana were recorded in 1986, since then an aggregate total of 225,478 people are estimated to be living with HIV in the Country [1]. Ghana has recorded significant progress in the fight against HIV/AIDS over the last decade with current infection rates plateauing around the prevalence of 1.3\% among the general population aged 15-49 years [2-4]. However there still exist significant challenges especially amongst Key Populations. Key populations are communities of people most susceptible to HIV infection, these include men who have sex with men (MSM), female sex workers (FSW), drug users and transgender people. Within these communities the prevalence is about 15 times higher than the general population, a fact that plays a key role in the HIV transmission dynamics. But with the constant interactions between them, it is impossible to dissociate key populations from the general population in terms of HIV spread and public health implications thereof. A significant portion of key population reports having experienced violence from police and other members of society [5]. This situation further alienates this subpopulation and further excludes them from seeking support and treatment from the right avenues.

The Law enforcement agencies especially Police are an essential sector in determining the risk environment for HIV for most key populations and other marginalized groups. In the global response to HIV, the key role of the police has been well recognized and integrated in many developed countries. The situation is however different in most of the developing and transitional world, where there is a large literature on police serving as obstacles to effective HIV responses, and their role in violations of the human rights of these key populations [6]. Since such matters are still criminalised to some extent in most of the developing world, these people are thus targeted by police and often suffer brutality at their hands. 
There is therefore an urgent need for change in police culture and behaviour. Such change can only be implemented through peer education and engagement in partnerships with other key stakeholders, to encourage awareness of each partner's standpoints and concerns. To develop such measures and policies would require an understanding of the level of knowledge the police personnel have on such matters. This study therefore seeks to evaluate the understanding of the Police on their role in identifying and interacting with key populations. And also to educate them on how to interact properly with them so as not to jeopardize the gains already made in the fight against HIV in Ghana.

\section{Methodology}

The Ghana Police Service AIDS Control program with support of the Ghana Country Office of UNFPA designed and implemented a program in 5 Regions and some Headquarters formations out of a total of 14 police regions. These regions were selected based on their high HIV Prevalence and the existence of hot spots (where key population activities usually take place). The program targeted 611 police personnel on three levels (Senior Police officers (SPO), Inspectorate/Middle level and the operational/other ranks) as indicated in Figure 1 below. Personnel were drawn from CID (Criminal Investigation Department), DOVVSU (Domestic Violence and Victims Support Unit) and the uniformed/patrol personnel. The majority of respondents were selected from the operational rank/other ranks because they are usually the ranks in direct contact with the key populations.

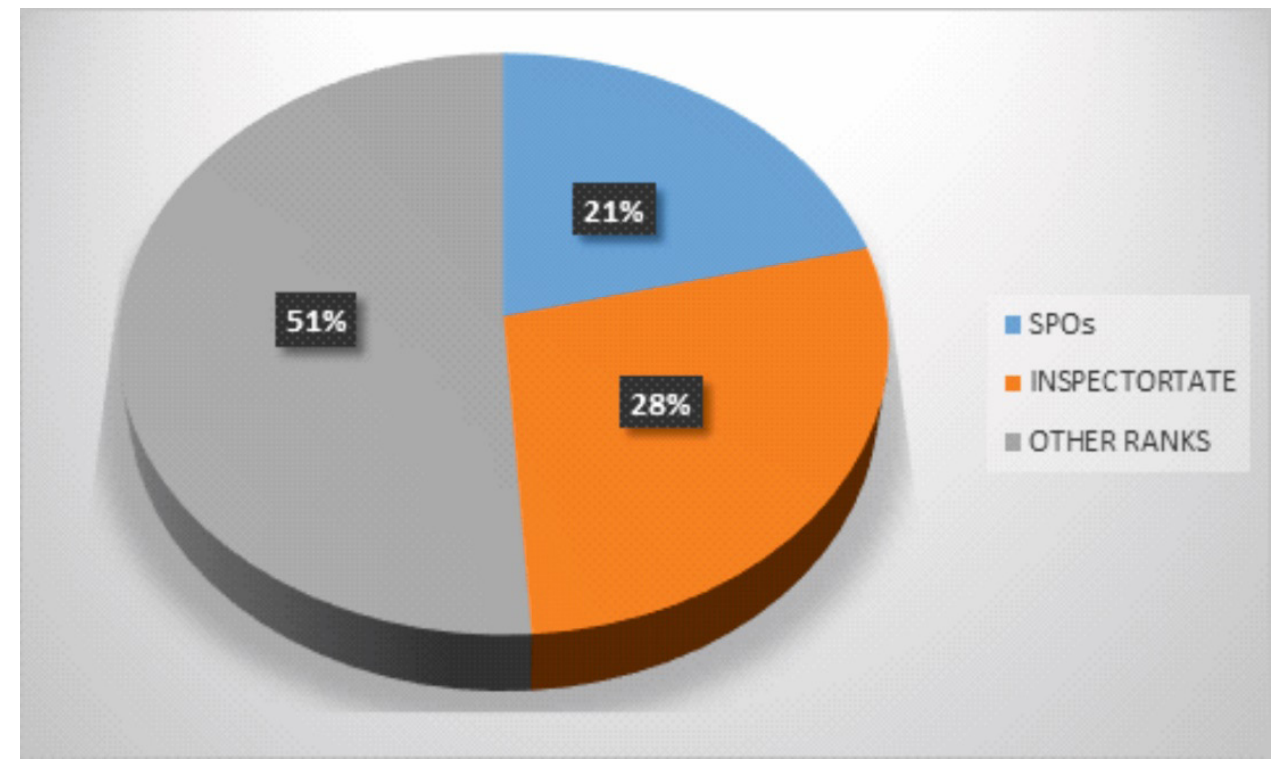

Figure 1: Table displaying the distribution of respondents

The research adopted the process of focus group discussion (FGD) to address specific questions developed to satisfy the objectives of the research. The sessions focused on the epidemic of bad laws that criminalize populations and behaviours and stand in the way of progress in addressing HIV. The interview guide for the focus group discussion sought to address topics such as;

- How the Police would identify a Gender and Sexual Minority(GSM)/Key Population(KP)

- Definition of the laws that classify Key Populations

- What constitutes the causation of a sexual offence/offences against public morals

In each region, 6 or 7 members were drawn for one session of the FGD from the total participants drawn. Up to 5 sessions were held in each region lasting for up to an hour. The rank of the respondents was recorded along with their responses, charts were then generated to show the distribution of the percentages in the various ranks and the appropriateness of their responses. This was followed by sensitization programs to address issues that came out from the Focus Group Discussions.

\section{Results and Discussion}

The ability of respondents to understand the laws and interpret them ranged for one being an SPO (77\%) to working at DOVVSU (70\%) to operational men (38\%) respectively.

When respondents were asked how does the Criminal Offences Act describes the offences of Solicitation or unnatural carnal knowledge, in all instances, participants could not define or state the key ingredients of the law as stated in the Criminal Offences Act. (Ref. Sect. 104 \& Sect 273-276 of the Criminal Offences Act 29/1960.) The response levels were SPO (62\%) DOVVSU (70\%) with Other Ranks being 59\% respectively. They were stating bits and pieces of the laws and these are not enough to prosecute an individual under such offences. 
The third topic of discussion was centred on the question; what constitutes the causation of sexual offence/offences against public morals. In answer to these questions, discussants dwelt mostly on perceptions as facts. The way of dressing, the time of the day, the way of walking and where one is spotted constituted most of the responses of law enforcement officials. Appropriateness of responses ranged from DOVVSU (63\%) to SPOs (59\%) and Other Ranks (41\%).

The higher ranking officers were more conversant with the proper interpretation of the laws and the other topics discussed than the lower rank officers, this could be due to the higher ranking officer's more years of service or in most cases more training and education. Majority of respondents from DOVVSU also showed familiarity with the proper interpretation of the laws mainly due to the core function of their unit, which deals with human right abuses towards women and children. The responses given on the method of identification of a key population were clearly unsatisfactory and inappropriate.

The Ghana AIDS Commission in its fight against the spread of HIV promotes condom use, especially by key population so using that as an indicator of wrong doing is clearly at odds with that policy. What was evident during these discussions was the strong correlation between the level of training and the respondent's ability to properly interpret and understand the application of the laws. This further underscores the need for sensitisation training and more of such forums to expose all wrongful practise and educate on appropriate measures. A similar exercise carried out in Kenya has improved relations between the Police and Key populations leading to wider access to health services by this vulnerable group [7]. At the heart of discussions was the fact that the rank in most contact with the key population could not properly interpret or understand the laws and their application. What these interactions showed was that getting the services to those that need them most is not possible in this context. Creation and application of the law is often based on prejudice, fear, myth and not science or evidence. And the problem is growing. The lack of enforcement of protective laws is problematic while there is an increase in intolerance and rights violations of male and female sex workers.

\section{Lessons Learnt}

Participants were shown a documentary on how the Police abuse the rights of these Key Populations with reckless abandon. Various scenarios of abuse were highlighted and this put participants in a sombre mood with majority bowing their heads in shame and unbelief.

The issue of abuse of rights of KPs featured prominently. At the end of sessions, participants agreed on the following

$\checkmark$ Police must be more professional in their dealings with every segment of society

$\checkmark$ Most senior officers stated that even though they try to protect the rights of these KPs they are compelled to go after them due to political and societal pressure.

$\checkmark$ Morality should and must be decoupled from law enforcement

$\checkmark$ There should be greater supervision of personnel especially the patrol teams.

$\checkmark$ The law enforcement must constantly dialogue with the judiciary in order to protect the rights of KPs

\section{Next Steps}

Acceptance is a major breakthrough to reform. This program has received the blessings of the Police administration and has taken the steps to punish perpetrators of abuse of KPs through meaningful engagement with key stakeholders that would result in the following:

$\checkmark$ Consensus building

$\checkmark$ Efficient use of available resources

$\checkmark$ Sustainability of the program

$\checkmark$ Ownership/buy-in

$\checkmark$ Transparency

We intend to roll out the program to all Police Regions and Districts in the country in order to change the mindset of law enforcement officials towards KPs even though there are pockets of dealing with divergent views and the challenges of a democratic process.

\section{Conclusion}

From the study it was evident that a higher level of training correlates strongly to the proper interpretation and understanding of the application of the laws. What was obvious to the participants after the interactions was that the application of the law is often times predicated on prejudice, fear, myth and not science or evidence. This further underscores the need for sensitisation training and more of such forums to expose all wrongful practises and educate on appropriate measures.

Though the laws do not allow or permit commercial sex activities in the country, it is also believed that to reach the national HIV response goal or in other to reduce HIV prevalence certain concessions may need to be made. The public health approach, 
considers that people should have access to HIV treatment, other healthcare facilities and tailor made treatment packages. These packages including treatment, advocacy as well as educational packages such as human rights empowerment, would greatly help to reduce infections among key populations. Therefore, members of key populations shouldn't be ostracized and pushed into the dark where we would have difficulties reaching them with such crucial packages.

\section{Acknowledgement}

The authors are grateful to the UNFPA office, Accra for providing the financial support for this project. Unreserved appreciation also goes to the Ghana Police Service AIDS Control program for their support.

\section{References}

1. HIV Sentinel Survey (HSS) Report (2010) National AIDS/STI Control Program (NACP)/Ghana Health Service (GHS).

2. Ghana AIDS Commission (2013) National HIV and AIDS, STI Policy.

3. Ghana AIDS Commission (2014) Ghana Country AIDS Response Progress Report.

4. Ghana AIDS Commission (2012) Ghana Country AIDS Progress Report.

5. Middleton LS (2013) Technical Paper: Review of Training and Programming Resources on Gender-Based Violence against Key Populations. USAID's AIDS Support and Technical Assistance Resources, AIDSTAR-Two, Task Order 2 and the International HIV/AIDS Alliance, Arlington, VA.

6. Law Enforcement and HIV Network (2014) Consultation on Police and HIV.

7. Scheibe A, Howell S, Müller A, Katumba M, Langen B, et al. (2016) Finding solid ground: law enforcement, key populations and their health and rights in South Africa. J Int AIDS Soc 19. 